This is an Accepted Manuscript of an article published by Taylor \& Francis in Information \& Communications Technology Law on 03/01/17, available online: http://www.tandfonline.com/doi/full/10.1080/13600834.2017.1269871 
Privacy implications and liability issues of Autonomous Vehicles

Dr Lisa Collingwood

Faculty of Business and Law, Kingston University, Kingston Upon Thames, UK +44 (0)208 417 5210, Lisa.collingwood@ kingston.ac.uk.

Page 2 of 25 


\title{
Privacy implications and liability issues of Autonomous Vehicles
}

\begin{abstract}
Autonomous vehicles have the potential for a variety of societal benefits. Individual mobility can be expanded to parties including the physically challenged, the elderly and the young. However, this article will consider two associated aspects of autonomous driving:
\end{abstract}

i. privacy implications; and

ii. issues of liability.

Despite the many advantages of autonomous or connected vehicles, the downside in respect of privacy is that the ability to move about in relative anonymity will be lost. A secret rendezvous with a lover will be a thing of the past because the data bank associated with such vehicles will include information regarding exactly who is riding, where the passengers were picked up and dropped off, at what time and what route was taken. This information is a legitimate (and potentially very valuable!) business asset of the companies that own and operate autonomous vehicle fleets, who rely on such data to analyse how many vehicles are needed, in which locations and when they should be charged or re-fuelled, but the consequences on privacy (and the susceptibility of cyber attack) are tangible.

Similarly, whilst one of the major advantages of autonomous driving is that traffic accidents may be virtually eliminated, the fact is that people will die in accidents involving autonomous vehicles. Therefore, in autonomous driving, a key question is that of liability and, specifically, where liability should reside in the event of an accident. 
This article considers how best to exploit autonomous vehicle innovation whilst, at the same time, securing the type of regulation appropriate to deal with the issues raised above.

Keywords: Autonomous vehicles; technological advancement; privacy; liability at law; policy/regulation. 


\section{Introduction}

Autonomous vehicles may be described as computer-controlled vehicles that drive themselves by relying on a number of data sources to assess the driving environment and to control the operation of the vehicle ${ }^{1}$. There are a wide range of possible types of autonomous vehicles, all of which supplant human drivers with artificial intelligence, meaning that a (human) driver does not need to be present at all ${ }^{2}$. Autonomous vehicles might span buses, trucks, taxis, emergency vehicles, and the like ${ }^{3}$. This article concentrates on autonomous vehicles as personal vehicles that are used by individuals for means of transportation on public roads. These are contrasted with semiautonomous vehicles, which use automation for a variety of tasks, but still retain some degree of human control. For example, Tesla's Model S, available for purchase since 2012, has four features (auto steer, auto lane change, auto park and side collision avoidance), which, when working in concert with adaptive cruise control, enable semiautonomous driving ${ }^{4}$. Whilst the focus of the article is on (fully) autonomous vehicles, semi-autonomous vehicles are considered for contextual purposes where appropriate. Similarly, whilst much of the research in this area comes from the US, despite the differences in laws, culture, etc between the UK and the US, there are many issues relating to autonomous vehicles that are common to both jurisdictions and, hence, US materials are referred to in this article as appropriate, not least because the US experience may suggest some possible solutions applicable in English law.

It has been argued that autonomous vehicles offer a wealth of social and economic advantages that could profoundly change our lives for the better ${ }^{5}$. They will arguably make driving easier, allow people to be more productive by enabling them to perform tasks other than driving (such as reading, texting, sleeping etc), reduce emissions, ease

\footnotetext{
${ }^{1}$ See further below and D Glancy, "Privacy In Autonomous Vehicles" (2012) 52 Santa Clara L. Rev. 1171, 1174.

2 Department of Transport, "The Pathway to Driverless Cars" (2015), 16. Report available at https://www.gov.uk/government/uploads/system/uploads/attachment_data/file/401562/pathwa y-driverless-cars-summary.pdf, last accessed 25 April 2016.

3 D Glancy, "Privacy In Autonomous Vehicles" (2012) 52 Santa Clara L. Rev. 1171, 1174

${ }^{4}$ See http://www.wired.com/2015/10/tesla-self-driving-over-air-update-live/, last accessed 21 June, 2016.

${ }^{5}$ Department of Transport, "The Pathway to Driverless Cars" (2015), 6. Report available at https://www.gov.uk/government/uploads/system/uploads/attachment_data/file/401562/pathwa y-driverless-cars-summary.pdf, last accessed 25 April 2016.
} 
congestion and offer greater mobility to a wider range of people ${ }^{6}$ than ever before ${ }^{7}$.

Accident avoidance is a major incentive. Worldwide, there are about 1.25 million traffic fatalities every year ${ }^{8}$ and it has been estimated that over $90 \%$ of road accidents are the fault of drivers ${ }^{9}$. Cars driven by human beings kill several thousands of people each year in the UK alone, for example. In 2014, the number of people killed in UK road accidents was 1,775 ( $+4 \%$ on 2013$)$, there were 194,477 casualties of all severities in reported road traffic accidents during 2014 ( $+6 \%$ on 2013) and, in the same year, c. 240 people were killed in accidents where at least one driver was over the drink drive limit (unchanged from 2013) ${ }^{10}$. It has also been estimated that driver impairment related to drugs was a contributory factorin reported road accidents resulting in 60 deaths ${ }^{11}$. The statistics also do not include the near misses so the real figure could be considerably higher. By removing the human element, autonomous driving technology could dramatically reduce these figures. For example, a recent UK study carried out by the trade body, the Society of Motor Manufacturers \& Traders (SMMT), has estimated that, by 2030 , a $25 \%$ penetration of autonomous fleet would mean that 2,500 more people would be alive than there might have been otherwise and the number of accidents will fall by 25,000 per annum ${ }^{12}$. A US study has projected that converting $10 \%$ of the U.S vehicle fleet to autonomous vehicles would reduce the number of yearly accidents by 211,000 and save 1,100 lives; if this rises to $90 \%$, the number of accidents avoided

\footnotetext{
${ }^{6}$ Including disabled, elderly, or young people and others who may simply not want to drive or be concerned about their ability to do so.

${ }^{7}$ Department of Transport, "The Pathway to Driverless Cars" (2015), 16. Report available at https://www.gov.uk/government/uploads/system/uploads/attachment_data/file/401562/pathwa y-driverless-cars-summary.pdf, last accessed 25 April 2016.

${ }^{8} \mathrm{http} / / / \mathrm{www} . w h o . i n t / m e d i a c e n t r e / f a c t s h e e t s / f s 358 / \mathrm{en}$, last accessed 21 April 2016.

9 http://cyberlaw.stanford.edu/blog/2013/12/human-error-cause-vehicle-crashes, last accessed 21 April 2016.

${ }^{10} \mathrm{http}$ ://www.racfoundation.org/motoring-faqs/safety, last accessed 21 April 2016.

${ }^{11}$ http://webarchive.nationalarchives.gov.uk/20100921035225/http://northreview.independent.go v.uk/report, last accessed 30 June 2016. Driving while under the influence of drugs is an offence under the Road Traffic Act 1988 with penalties similar to those for driving while under the influence of alcohol. Section 56 and Schedule 22 of the Crime and Courts Act 2013 introduced a new offence of driving while over a prescribed drug limit. This came into force in England and Wales on 2 March 2015. See http://researchbriefings.files.parliament.uk/documents/SN02884/SN02884.pdf, last accessed 30 June 2016.

${ }^{12}$ KPMG, "Connected and Autonomous Vehicles: The UK Economic Opportunity (Report) (March 2015).
} 
could reach 4.2 million per annum, with 21,700 lives saved $^{13}$. Hence, autonomous vehicles will arguably make driving a safer proposition. This comes down to the fact that failing to look properly, being intoxicated, misjudging other road users' movements, being distracted, careless or in too much of a hurry are the most common causes of collisions on UK roads ${ }^{14}$. Automated vehicles will not make these mistakes. Accordingly, the computer is simply a better driver than a human. Better at maintaining a steady speed, at keeping its "eyes" on other drivers or pedestrians and better at making rapid-fire adjustments. Moreover, the computer does not get distracted, it can clearly perceive cyclists and pedestrians, reacting instantly to imminent danger and it does not fall asleep (unless ordered to) and these variables have a major impact on accident avoidance. Put simply, traffic accidents may be virtually eliminated as a consequence of this technology.

There are, therefore, clearly several substantive benefits of autonomous vehicles and, with renewed governmental and other support, the technological progress inherent in such vehicles has been prolific and is only likely to improve. Autonomous vehicles have undergone a rapid metamorphosis since they first appeared as a response to a 2002 announcement by the US Defense Advanced Research Projects Agency (DARPA ${ }^{15}$ ) that they would fund a driverless car competition. In the first competition, which took place in 2004, none of the vehicles finished the route, but the scene was set for future challenges. The following year, five vehicles successfully completed the $212 \mathrm{~km}$ (132 mile) off-road course. The third event, the DARPA Urban Challenge ${ }^{16}$ took place in 2007 and extended the initial Challenge to autonomous operation in a mock urban environment. The technological innovation from these Challenges soon metamorphosed in to the commercial arena and, in 2008, Google kickstarted its own self-driving car project $^{17}$, building a range of prototype vehicles which have racked up over a million

${ }^{13}$ Eno Centre for Transportation, "Preparing a Nation for Autonomous Vehicles : Opportunities, Barriers and Policy Recommendations" (Report) (2013) .

${ }^{14}$ Department of Transport, "The Pathway to Driverless Cars" (2015), 13. Report available at https://www.gov.uk/government/uploads/system/uploads/attachment_data/file/401562/pathwa y-driverless-cars-summary.pdf, last accessed 25 April 2016.

${ }^{15}$ DARPA is a research organization of the United States Department of Defense. DARPA's role is to spur innovation. See http://www.darpa.mil, last accessed 21 April 2016.

${ }^{16} \mathrm{http}: / /$ archive.darpa.mil/grandchallenge, last accessed 21 April 2016.

${ }^{17}$ https://www.google.com/selfdrivingcar, last accessed 21 April 2016. 
miles on public roads, whilst maintaining a strong safety profile ${ }^{18}$. These self-driving cars are no longer a rare sight on Californian roads. Reportedly over 100 autonomous vehicles from a dozen manufacturers are now being tested in public, covering hundreds of thousands of kilometres on US roads each year ${ }^{19}$. In response to the perceived demand for personal autonomous vehicles, Elon Musk, the CEO of Tesla, has suggested that completely driverless vehicles will be likely to be available in two years ${ }^{20}$. By contrast, the UK Government suggests that most commentators do not expect vehicles capable of fully autonomous operation on public roads to become available until at least the 2020s, fuelled by developments in vehicle automation technology over the short to medium term ${ }^{21}$. Accordingly, trials of autonomous vehicles ${ }^{22}$ began in the UK in February 2015 in selected cities (Greenwich, Milton Keynes, Coventry and Bristol ${ }^{23}$ and are due to be trialled in London later in $2016^{24}$ ). Thus, in the space of a few years, autonomous vehicle technology has evolved from a niche research arena into what could become a vast commercial offering. Whilst much consideration has been given to harnessing this technology into the commercial sphere, the same cannot be said of the regulatory environment, the apparatus for which is arguably "stuck in the atomic age as the ... technology thrusts into the fully networked age" 25 and two key concerns raised by this technology are explored below : privacy implications and issues of liability

${ }^{18}$ See Michael Rundle, "Google's self-driving cars have been in 11 accidents in six years" (May 12, 2015), Wired, available at http://www.wired.co.uk/news/archive/2015-05/12/google-selfdriving-cars-accidents, last accessed 25 April 2016. However, see M Robbins, "Statistically, self-driving cars are about to kill someone. What happens next?" The Guardian (London 14 June 2016).

${ }^{19} \mathrm{http} / / / \mathrm{www}$.economist.com/news/science-and-technology/21696925-building-highly-detailedmaps-robotic-vehicles-autonomous-cars-reality, last accessed 21 June 2016.

${ }^{20} \mathrm{https://www.theguardian.com/technology/2016/jan/11/elon-musk-tesla-cars-no-driver-model-}$ s, last accessed 21 April 2016.

${ }^{21}$ Department of Transport, "The Pathway to Driverless Cars" (2015), 16. Report available at https://www.gov.uk/government/uploads/system/uploads/attachment_data/file/401562/pathwa y-driverless-cars-summary.pdf, last accessed 25 April 2016.

${ }^{22}$ Admittedly with suitably qualified 'test drivers' who will be supervising the vehicle and be ready and able to take over active control if necessary. See Department of Transport, "The Pathway to Driverless Cars" (2015), 6. Report available at https://www.gov.uk/government/uploads/system/uploads/attachment_data/file/401562/pathwa y-driverless-cars-summary.pdf, last accessed 25 April 2016.

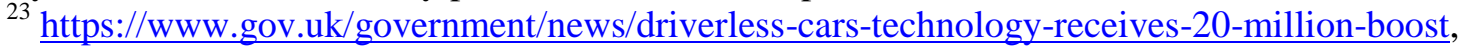
last accessed 22 April 2016.

${ }^{24} \mathrm{http} / / / \mathrm{www} . w i r e d . c o . u k / n e w s / a r c h i v e / 2016-01 / 29 /$ driverless-autonomous-cars-london, last accessed 22 April 2016.

${ }^{25}$ E Goodman, "Self-driving cars: overlooking data privacy is a car crash waiting to happen", The Guardian (London 8 June 2016). 
related to autonomous vehicles. These are evaluated in tandem so as to shed light on methods for their regulation and to address an observed gap in the available literature to date $^{26}$.

\section{Privacy implications}

Whilst there are a variety of potential privacy implications applicable to autonomous vehicles $^{27}$, privacy as control over private information and misuse of that private information forms the focus of this article. The analysis commences with a discussion of the ways in which the very mechanics of autonomous vehicle technology give rise to concerns surrounding privacy as control over information and proceeds to explore the basis upon which reasonable expectations of privacy might be made out in this context.

To set the scene, autonomous vehicles incorporate rotating lasers to build a detailed picture of the world, taking around a million readings per second, plus a combination of dozens of sonar, radar and cameras to capture and provide additional data that make them aware of their surroundings. In addition, they require cellular or wireless connections to alert vehicles to hazardous conditions and provide real-time traffic updates, allowing autonomous vehicles to automatically route around traffic jams ${ }^{28}$. As Glancy notes, when a vehicle records such data and associates it with an identifiable individual, the data becomes personal information ${ }^{29}$ and this creates various privacy fears, not least because of the huge amount of data collected and possibly stored, either in the vehicle itself or sent elsewhere (estimates have suggested that c. 1 Gigabyte of data is collected by autonomous vehicles every second $)^{30}$. Glancy identifies three separate areas of concern which, because they relate to privacy as control over information, are pertinent to the matters considered in this article ${ }^{31}$ : autonomy privacy

${ }^{26}$ E Goodman, "Self-driving cars: overlooking data privacy is a car crash waiting to happen", The Guardian (London 8 June 2016).

${ }^{27}$ See subsequent text and, in general, D Glancy, "Privacy In Autonomous Vehicles" (2012) 52 Santa Clara L. Rev. 1171.

${ }^{28}$ T Lee, "Self-Driving Cars Are a Privacy Nightmare. And It's Totally Worth It" Washington Post (Washington 21 May 2013).

${ }^{29}$ D Glancy, "Privacy In Autonomous Vehicles" (2012) 52 Santa Clara L. Rev. 1171, 1175. Issues of data protection are considered below.

${ }^{30}$ F van den Boom, "If autonomous cars could talk!" (2015) 135 Privacy Laws \& Business International 17, 17.

${ }^{31}$ Matters pertaining to "Big data" are largely beyond the remit of this article. 
interests, information privacy interests and surveillance privacy interests (which combine both autonomy and personal information interests) ${ }^{32}$. Personal autonomy is concerned with individual control and self-determination - the ability of people to make independent choices about themselves and "the desire to avoid being manipulated or dominated wholly by others" ${ }^{\prime 3}$. In respect of personal autonomy, inherent in the very nature of autonomous vehicles is the idea that they will take autonomy away from a human user, principally because autonomous vehicles will assume control over the way in which people move from place to place ${ }^{34}$. However, it should also be noted that, for some people (for example, disabled persons, the elderly, and those with impaired driving abilities), autonomous vehicles could provide enhanced personal autonomy and self-determination about when, how, and with whom to travel, offering more individual travel choices than such users now enjoy, including the otherwise unavailable independence of traveling alone. Glancy argues that, in the future, when an individual chooses either to drive or to use an autonomous vehicle, such a choice will be an exercise of positive autonomy ${ }^{35}$. It is partly for this reason, that Glancy likens autonomous vehicles to delegated agents, tasked with making particular assigned choices or decisions ${ }^{36}$.

Whilst autonomy choices could be a welcome distraction for certain users, personal information privacy interests are arguably of broader concern because, once this technology is widely adopted, autonomous vehicle manufacturers and other interested parties will have a myriad of information on where you are driving and how you are getting there. Information related to autonomous vehicles will be likely to include such matters as where you have been, what you have encountered along the way and your driving habits. Thus, for example, advertising opportunities could be extremely prevalent because, depending upon their design, autonomous vehicle users could be treated as captive audiences for location-based targeted advertising. Autonomous

\footnotetext{
${ }^{32}$ D Glancy, "Privacy In Autonomous Vehicles" (2012) 52 Santa Clara L. Rev. 1171, 1173. It is, however, also recognised (page 1207) that use of autonomous vehicles for surveillance purposes could compromise something more than just autonomy and personal information privacy interests and that it could threaten the political and social well-being of society.

${ }^{33}$ Westin, A, Privacy and Freedom (Atheneum 1967) 7.

${ }^{34}$ D Glancy, "Privacy In Autonomous Vehicles" (2012) 52 Santa Clara L. Rev. 1171, 1186.

${ }^{35}$ D Glancy, "Privacy In Autonomous Vehicles" (2012) 52 Santa Clara L. Rev. 1171, 1193.

${ }^{36}$ D Glancy, "Privacy In Autonomous Vehicles" (2012) 52 Santa Clara L. Rev. 1171, 1190.
} 
vehicles could, therefore, be instruments that actively facilitate intrusion ${ }^{37}$. Additionally, as Glancy notes, data from autonomous vehicles could convey sensitive information about where the user is and what he or she is doing, as well as a comprehensive log of places the user visited and will visit in the future. For some potential autonomous vehicle users, relying on an autonomous vehicle could pose a Hobson's choice-either to take this autonomous vehicle mode of personal transport that tracks your every movement, or to have no individual vehicle mobility at all ${ }^{38}$. This is relevant because personal information from autonomous vehicles can be correlated with other information. For example, the location where the vehicle is regularly parked overnight (e.g., in a high-income neighbourhood) could be used to profile the likely user (e.g., as wealthy) and to predict the user's actions (e.g., likely to shop at high-end shops). Thus, autonomous vehicle technology could compromise users' privacy by transmitting not only "the present location of an autonomous vehicle user [and] that person's past travel patterns," but also "his or her future travel plans" ${ }^{39}$. Finally, as a consequence of the pervasive scrutiny of those who travel in autonomous vehicles, surveillance privacy interests are impacted because comprehensive personal information collection could be used to profile, predict, and possibly manipulate the behaviour of autonomous vehicle users (to stay away from the seedy side of town or to avoid attending a Trade Union meeting, for example; equally, it is arguable that such data might help authorities to detect crime - for instance, by tracking users who regularly visit known drug dens). The potential use of autonomous vehicles as tools for comprehensively tracking (legal and illegal) activities will undoubtedly affect privacy interests associated with concerns about surveillance ${ }^{40}$, which are also addressed subsequently in this article in relation to cyber attack.

The culmination of the above discussion is that the ability for individuals to retain control over their private information as it flows through connected cars is a very real concern in the context of autonomous vehicles. A vast amount of data will be collected

\footnotetext{
${ }^{37}$ D Glancy, "Privacy In Autonomous Vehicles" (2012) 52 Santa Clara L. Rev. 1171, 1194. However, a counter argument is that this is no different to the situation online shoppers find themselves in.

${ }^{38}$ D Glancy, "Privacy In Autonomous Vehicles" (2012) 52 Santa Clara L. Rev. 1171, 1186.

${ }^{39}$ D Glancy, "Privacy In Autonomous Vehicles" (2012) 52 Santa Clara L. Rev. 1171, 1196.

${ }^{40}$ D Glancy, "Privacy In Autonomous Vehicles" (2012) 52 Santa Clara L. Rev. 1171, 1172.
} 
and stored by these vehicles ${ }^{41}$. This data is likely to be highly valuable to a number of interested parties and it remains unclear who owns the generated data and what the restrictions concerning onward transmission or usage might be. The question marks over data ownership and dissemination mean that privacy fears are tangible. Given that living in a digital age has already had major consequences on privacy concerns, it is fair to argue that individuals are becoming more aware of their privacy, and its value in democratic society, than they used to be ${ }^{42}$. Consequently, privacy concerns appear to be gaining in momentum, culminating in a groundswell in public sympathy, of which legislators and regulators must be aware ${ }^{43}$. They will need to address questions, such as what uses are made of the personal data collected by autonomous vehicles, why it is being collected, how it will be used, how long is reasonable for it be kept, and who will and will not have access to it? Glancy has argued that, without appropriate legal protections for privacy, autonomous vehicles could well meet "market resistance" from potential users who perceive autonomous vehicles as threats to their privacy ${ }^{44}$. However, it may be countered that where the benefits of technology are considered to be vast (as they are expected to be here), consumers are arguably likely to sign up in droves. For example, there has been little market resistance to the adoption of mobile phone technology ${ }^{45}$. Notwithstanding this evaluation, the ability to retain control over private information means that data protection and privacy principles will need to be developed in order to work alongside the advance of autonomous vehicle technology.

For example, an autonomous vehicle can be designed to minimize personal information that it generates, collects, or retains and personal information from autonomous vehicles can be encrypted and rendered anonymous. This has its own implications because encrypting the data would then defeat the possible use of it to detect illegal activity. Arguably, this could be addressed by an appropriately worded court order imposing an obligation on the holder of the data to disclose information in accordance with that court

${ }^{41}$ See, further, F van den Boom, "If autonomous cars could talk!" (2015) 135 Privacy Laws \& Business International 17, 17.

${ }^{42}$ J Jarvis, Public Parts : How Sharing in the Digital Age Improves the Way We Work and Live (Simon and Schuster, 2011) 102.

${ }^{43}$ Wray, R, 'Campaigners claim victory in battle against online snooping technology", The Guardian, (London 6 July 2009).

${ }^{44}$ D Glancy, "Privacy In Autonomous Vehicles" (2012) 52 Santa Clara L. Rev. 1171, 1225.

45 https://www.washingtonpost.com/news/wonk/wp/2013/05/21/self-driving-cars-are-aprivacy-nightmare-and-its-totally-worth-it/, last accessed 30 June 2016. 
order and this would only be a viable mechanism where the data holder has stored the original, pre-anonymised, data. Such matters highlight the importance of developing the complicated rules of the regulatory regime that applies with the reality of this new technology. Under the Data Protection Act 1998, where personal information is, as here, necessary to perform a particular function, the information can be kept for no longer than is necessary once that purpose has been accomplished ${ }^{46}$. This is important because being clear in advance about what the technology will and will not do in relation to user data is essential for take-up of the technology. Better data retention policies could, thus, enhance users' privacy. If companies delete information about users' locations promptly, that would reduce the potential for the information to be abused later and applicable measures of data anonymisation and encryption, duly overseen by an appropriate regulatory body, could go some way towards protecting personal information as well as augmenting the legitimate usage of the data. It has also been argued that establishing standards of data management, in conjunction with the requirement to store data in a 'blackbox' fashion for examination in the event of a collision, or other incident, would also be worthwhile ${ }^{47}$.

Further, it may also be argued that the intelligence that drives an autonomous vehicle could be sufficiently developed to make privacy protection part of the architecture of autonomous vehicles $^{48}$. The State of California, for example, although it requires that all autonomous vehicles preserve detailed records of the thirty seconds leading up to an accident, also demands that the "manufacturer of the autonomous technology installed on a vehicle shall provide a written disclosure ... that describes what information is collected by the autonomous technology equipped on the vehicle" ${ }^{49}$. However, to date, US state regulations have arguably failed to address the wider problems associated with the collection, use, storage and dissemination of data generated by autonomous vehicles $^{50}$.

\footnotetext{
${ }^{46}$ Data Protection Act 1998, Schedule 1, Part I.

${ }^{47}$ G Yeomans, "Autonomous Vehicles: Handing over Control - Opportunities and Risks for Insurance" 9 (Report) (2014), available at https://www.lloyds.com/ /media/lloyds/reports/emerging\%20risk\%20reports/autonomous\%20 vehicles\%20final.pdf, last accessed 28 April 2016.

${ }^{48}$ D Glancy, "Privacy In Autonomous Vehicles" (2012) 52 Santa Clara L. Rev. 1171, 1237-8.

${ }^{49}$ Cal. Veh. Code $\$ 38750(b)(1)$ (West 2013).

${ }^{50}$ E Goodman, "Self-driving cars: overlooking data privacy is a car crash waiting to happen", The Guardian (London 8 June 2016).
} 
Given the concerns identified above, these matters need to be at the forefront of domestic legislative thinking in relation to matters of privacy as control over private information in the context of autonomous vehicles. It may also be necessary to revisit reasonable expectations of privacy analysis in this context. Whilst this formulation has become a familiar way to make an initial determination of whether legal protection for privacy interests would be appropriate under particular circumstances, inquiring into reasonable expectations of privacy in the context of autonomous vehicles is unclear ${ }^{51}$. For example, can it be argued that a driver has a reasonable expectation of privacy with respect to autonomous vehicle data? What is the position in relation to reasonable expectations of privacy on a public road? Whilst it has been accepted in the UK that a person's privacy rights may be infringed even in relation to things done in a public place $^{52}$, and therefore the claimant in Campbell had a reasonable expectation of privacy in relation to photographs of her leaving a rehabilitation clinic, this must be balanced against more recent Supreme Court judgment indicating that "[T]he taking of photographs in a public street must be taken to be one of the ordinary incidents of living in a free community" ${ }^{\prime 3}$. In $r e J R 38$, a child aged 14 who was suspected of involvement in criminal rioting, was unsuccessful in claiming that the publication of photographs in two newspapers engaged Article $8 \mathrm{ECHR}^{54}$ since there was no reasonable expectation of privacy in the circumstances. The Supreme Court held that even if Article 8 had been engaged, the interference was justified where publication was solely for the prevention and detection of crime ${ }^{55}$. Therefore, whilst one can make out a case for privacy in public, what is the position on a public road? Presumably, a reasonable expectation of privacy would stand where the information revealed was relevant to a claimant's health ${ }^{56}$, personal $^{57}$ or sexual relationships ${ }^{58}$, but not where required for prevention and detection of crime ${ }^{59}$. Overall, the suitability of applying reasonable expectations of privacy in respect of privacy on a public road and in the context of autonomous vehicles

${ }^{51}$ D Glancy, "Privacy In Autonomous Vehicles" (2012) 52 Santa Clara L. Rev. 1171, 1216.

${ }^{52}$ Campbell v Mirror Group Newspapers Ltd [2004] UKHL 22, [2004] 2 AC 457.

${ }^{53}$ re JR 38 [2015] UKSC 42, [2015] 3 WLR 155, [88] per Lord Toulson.

${ }^{54}$ Under Article 8 "(1) Everyone has the right to respect for his private and family life, his home and his correspondence".

${ }^{55}$ re JR 38 [2015] UKSC 42, [2015] 3 WLR 155.

${ }^{56}$ Campbell v Mirror Group Newspapers Ltd [2004] UKHL 22, [2004] 2 AC 457 [57].

${ }^{57}$ McKennitt v Ash [2006] EWCA Civ 1714, [2008] QB 73 [75].

${ }^{58}$ Mosley v News Group Newspapers Ltd [2008] EWHC 1777 (QB), [2008] EMLR 20 [104].

${ }^{59}$ re JR 38 [2015] UKSC 42, [2015] 3 WLR 155. 
is open to question and it is a question that will ultimately be the domain of the courts. This is because changes in attitudes, perceptions and aspirations of privacy mean that it is increasingly difficult to determine what form of expectation would be considered as reasonable and the degree by which a reasonable expectation of privacy would be diluted by the very mechanics of autonomous vehicle technology. This must, however, be balanced against the counter argument that autonomous vehicles may enhance privacy because they will become akin to (mobile) homes, in which individuals might eat, sleep and be entertained, and the high privacy expectations associated with homes or private residences ${ }^{60}$ are very different from the limited expectations of privacy afforded to individuals without this protective shell on an open, public, road. Furthermore, physical privacy may also be enhanced in such vehicles because they may allow for less intrusion from the street in to the car itself. Freeing carmakers and designers of their chief constriction (unreliable drivers) will allow them to invent novel creations - for example, designs which require less visual access / windows. This could of course have negative consequences if what's being transported is undesirable, offensive, dangerous, or illegal but the benefits in terms of physical privacy are clear.

In summary, autonomous vehicles generate personal information about the people who use them and the debate concerning the control over, ownership and misuse of this information necessitates an appropriate regulatory response. There is a strong argument to suggest that the emerging technology can be seen as a threat to user privacy and, as Glancy notes, ultimately, the future success of autonomous vehicles will depend in part on how well privacy interests and autonomous vehicles can work together. Given that assuring respect for user privacy is one of the best ways to foster trust and confidence in new technologies such as autonomous vehicles, this issue could be a real barrier to adoption of the technology if not properly addressed ${ }^{61}$.

Another notable part of this conundrum concerns issues of liability. In the discussion that follows, the focus is on how accidents involving autonomous vehicles will be treated at law. This commences with a consideration of a variety of scenarios in which

${ }^{60}$ D Glancy, "Privacy In Autonomous Vehicles" (2012) 52 Santa Clara L. Rev. 1171, 1219

${ }^{61}$ D Glancy, "Privacy In Autonomous Vehicles" (2012) 52 Santa Clara L. Rev. 1171, 1225-6. The debate also raises issues similar to those currently being discussed in the UK in relation to a new Investigatory Powers Bill. See http://www.wired.co.uk/article/surveillance-billgovernment-internet-history, last accessed 22 June 2016. 
liability apportionment, across a variety of players, might materialise at different junctures of autonomous vehicle technology development and deployment. Following this, the security and safety of the technological systems themselves is considered and the vulnerability to cyber attack deliberated.

\section{Issues of Liability}

The first accident involving an autonomous vehicle was reported on February 2016 when an autonomous vehicle hit the side of a passing bus ${ }^{62}$. Though a relatively minor accident, it effectively highlighted that the safety of autonomous vehicles cannot perhaps be taken for granted. Moreover, it has recently been argued that "[A]t some point, a car driving autonomously ... will cause a fatal accident" ${ }^{\prime \prime 3}$. There does seem something more sinister about a computer taking the life of an individual on a road rather than a fellow human being. Rightly or wrongly, we all arguably expect human error, whereas we do not afford the same degree of leniency to computers, which we anticipate will perform perfectly. Perhaps this explains why it was so striking in the 2015 film Ex Machina, when the life of the (flawed) human creator was snuffed out by his (seemingly perfect) computer creation. How will then accidents involving autonomous vehicles be treated at law?

At present in the UK, following a road traffic accident, primary liability rests with the user of the car, regardless of whether their actions cause the accident or not ${ }^{64}$. In most road traffic collisions there is a range of different people or bodies which may bear or share liability and civil law has traditionally played a central role in resolving the disputes that do arise. The degree to which civil law would apportion blame in the context of autonomous vehicles is unclear once automated systems controlling driverless vehicles are included in the mix of potential culpability ${ }^{65}$. What is clear is

\footnotetext{
${ }^{62}$ M Robbins, "Statistically, self-driving cars are about to kill someone. What happens next?" The Guardian (London 14 June 2016).

${ }^{63}$ Ibid.

${ }^{64}$ G Yeomans, "Autonomous Vehicles: Handing over Control - Opportunities and Risks for Insurance" 8 (Report) (2014), available at https://www.lloyds.com/ /media/lloyds/reports/emerging\%20risk\%20reports/autonomous\%20 vehicles\%20final.pdf, last accessed 28 April 2016.

${ }^{65}$ It will, therefore, be very interesting to see what sort of policies insurers draw up for users of autonomous vehicles in this hazy environment. It is speculated that insurers will reward technologies that will make vehicles safer. A reduction in insurance claims could lead to lower
} 
that, even with improved safety features, the possibility of collisions with conventionally driven vehicles and of pedestrians being hit by autonomous vehicles, whilst considerably lowered, remains. The fact is that people will die in accidents involving these vehicles ${ }^{66}$.

However, who is responsible and who pays for damage is uncertain because, following dispensability of an active human driver, autonomous vehicles shift responsibility for physically driving from the driver to the vehicle itself. From a legal perspective, the test of whether a person is physically driving a vehicle derived from $R v$ MacDonagh $^{67}$ is whether he or she is "in a substantial sense controlling the movement and direction of the car" ${ }^{\prime 68}$ and that "[T]here are an infinite number of ways in which a person may control the movement of a motor vehicle, apart from the orthodox one of sitting in the driving seat and using the engine for propulsion... Although the word 'drive' must be given a wide meaning, the courts must be alert to see that the net is not thrown so widely that it includes activities which cannot be said to be driving a motor vehicle in any ordinary use of that word in the English language."69 Therefore, the activity must also fall within the ordinary meaning of the word "drive" and although the word meant, essentially, to use the driver's controls for the purpose of directing the movement of the car, it did not extend to the activity of a person (such as MacDonagh) who was not in the car, had both feet in the road, and was making no use of the controls apart from an occasional adjustment of the steering wheel.

The point is that, with a fully autonomous vehicle, it is difficult to argue that any

premiums (See Department of Transport, "The Pathway to Driverless Cars" (2015), 24. Report available at https://www.gov.uk/government/uploads/system/uploads/attachment_data/file/401562/pathwa y-driverless-cars-summary.pdf, last accessed 25 April 2016). There will also likely be a resultant impact on the compensation culture that has prevailed in UK motor insurance claims to date. See

http://www.axa.co.uk/uploadedFiles/Content/Newsroom_v2/Media_Resources/Reports_and_P ublications/Downloads/AXA_UK_Compensation_Culture_Series/axa\%20whiplash\%20report final.pdf, last accessed 22 June 2016.

${ }^{66}$ M Robbins, "Statistically, self-driving cars are about to kill someone. What happens next?" The Guardian (London 14 June 2016).

${ }^{67} R v$ MacDonagh [1974] 1 QB 448. Here, the Appellant, whilst disqualified from driving, was pushing a car with his shoulder and was not physically in the car. He was charged with driving the car while disqualified, contrary to section 99 (b) of Road Traffic Act 1972, but his appeal was allowed and the conviction quashed.

${ }^{68}$ Ibid, per Lord Widgery CJ.

${ }^{69}$ Ibid. 
persons being carried in the vehicle could be described as driving. This is the position suggested in the US, following the announcement by vehicle safety regulators, the National Highway Traffic Safety Administration (NHTSA), that they will interpret 'driver' in the context of autonomous vehicles as referring to the self-driving system, and not to any of the vehicle occupants ${ }^{70}$. NHTSA have also said that the artificial intelligence system piloting a self-driving Google car could be considered the driver under federal law ${ }^{71}$. Notwithstanding the US stance, in the UK, it is uncertain whether the vehicle itself would be considered as driving for purposes of liability. The Department of Transport has recognised that the term 'driver' will become less clearly defined in the context of autonomous vehicles ${ }^{72}$ and it is certainly questionable whether the term would be applicable to autonomous vehicles or require refinement or redefinition and arguably "control" might be a better concept altogether. This raises a number of questions, such as who or what could be said to be controlling the vehicle? Could the owner and / or operator of the software controlling the vehicle be blamed for any collision or would the vehicle manufacturer or software provider be held responsible? Presumably, for vehicles operating autonomously, the manufacturer is likely to be liable for any accidents caused by defects in the design or functioning of the product and in its automated systems in the event that the technology should have avoided an accident, but failed to. In this context, Section 2(a) Consumer Protection Act 1987 would impose strict liability upon the producer of an autonomous vehicle if the vehicle was not as safe as 'persons are generally entitled to expect'. This prerequisite is likely to be met unless the vehicle was operated contrary to its instructions or warnings. However, could the owner of the car, who may not have been in it, be deemed responsible, even if not controlling the car's movement? Does liability fall back on to the manufacturer, vehicle supplier/importer or service / data provider? In a fully autonomous vehicle, once (human) drivers are out of the picture, liability for their actions presumably falls away. However, this would not stand where an occupant of the vehicle embarked upon a deliberate destruction of the hardware, for example. It

\footnotetext{
${ }^{70}$ See http://www.reuters.com/article/us-alphabet-autos-selfdriving-exclusiveidUSKCNOVJOOH, last accessed 23 June 2016.

${ }^{71} \mathrm{http}$ ://www.reuters.com/article/us-alphabet-autos-selfdriving-exclusive-idUSKCNOVJ00H, last accessed 23 June 2016.

${ }^{72}$ Department of Transport, "The Pathway to Driverless Cars" (2015), 18. Report available at https://www.gov.uk/government/uploads/system/uploads/attachment_data/file/401562/pathwa y-driverless-cars-summary.pdf, last accessed 25 April 2016.
} 
is also unclear who should assume responsibility if the occupants of vehicles with manual override did not intervene to avoid a collision but might have been able to do so : in other words, how is blame apportioned between a (human) driver and a car's automated system? How is this affected by the knowledge that the choice of a human driver to resume manual control, even in autonomous vehicles which may still offer a full set of controls to allow a driver to resume manual control if they so wish, would be entirely optional ${ }^{73}$. Since some of the attraction of autonomous vehicles is the opportunity for a user, who would otherwise need to be fully engaged in driving, to do something else or nothing at $\mathrm{all}^{74}$, it is conceivable that users of autonomous vehicles might not be expected to have any control over or awareness of driving. This will be likely to affect in-vehicle behaviour because car users would effectively be legally permitted to be distracted from driving. Users of autonomous vehicles could read a book, send a text or sleep, for example. But what will be the outcome if the passengers in an automated vehicle were intoxicated or engaging in inappropriate, or criminal, activity but had the ability to avert danger? Could they be liable in the event of an accident? Would they be found to have been contributorily negligent and be allocated some or all of the responsibility for the accident? Further, to what extent would the reach of criminal responsibility be curtailed in this scenario? Arguably, the unique features of autonomous vehicle technology will mean that many of the current criminal motor offences will have little or no application : unless the passenger retains some degree of control of the vehicle, offences such as speeding, drink driving, careless or dangerous driving will not apply.

In addition, if it is determined that (human) drivers will be required by law to be able to regain control from automated systems when required, what if they did not have time to prevent the accident? What if the accident was an inevitability in the extreme cases where the vehicle itself is unable to avoid it? How the vehicle subsequently reacts will be governed by its pre-programmed algorithms and its in-

\footnotetext{
${ }^{73}$ Department of Transport, "The Pathway to Driverless Cars" (2015), 18. Report available at https://www.gov.uk/government/uploads/system/uploads/attachment data/file/401562/pathwa y-driverless-cars-summary.pdf, last accessed 25 April 2016.

${ }^{74}$ D Glancy, "Privacy In Autonomous Vehicles" (2012) 52 Santa Clara L. Rev. 1171, 1184.
} 
built ethical solutions ${ }^{75}$. Anderson et al. recommend that liability rules be designed to encourage autonomous vehicle technology deployment whenever it is superior to average human drivers, even if errors, injuries, and deaths inevitably occur $^{76}$. Others have suggested that courts will tend to side with humans in some circumstances, rather than manufacturer's algorithms ${ }^{77}$. How liability will be apportioned among the interconnected web of manufacturers, traditional drivers, vehicle owners and operators et al in the years ahead remains an open question. Gurney, for example, suggests that the proper party to assume liability will vary depending on the nature of the autonomous car user and the ability of that person to prevent the accident ${ }^{78}$. Duffy and Hopkins advocate "strict liability to autonomous car owners" ${ }^{79}$, whilst Kalra et al contend that manufacturers will increasingly be liable for accidents caused by autonomous vehicles ${ }^{80}$, a position supported by Graham ${ }^{81}$. However, it should also be remembered that other countries will have different stances on liability, which may more readily find the manufacturer of an autonomous vehicle liable in the event of an accident ${ }^{82}$.

${ }^{75}$ See, on this point, J-F Bonnefon, A Shari and I Rahwan, "Autonomous Vehicles Need Experimental Ethics: Are We Ready for Utilitarian Cars?" Toulouse School of Economics, University of Oregon and Massachusetts Institute of Technology, arXiv:1510.03346v1 [cs.CY] 12 Oct 2015, which explores how to build "moral algorithms" in to autonomous vehicles.

${ }^{76}$ J Anderson, N Kalra , K Stanley, P Sorensen, C Samaras, \& O Oluwatola,

"Autonomous vehicle technology: A guide for policymakers" Santa Monica, CA:

RAND Corporation, Transportation, Space, and Technology Program (2014).

${ }^{77}$ See, further, A English, "Autonomous Cars : Is This the End of Driving?, The Telegraph (London 16 January 2014), available at http://www.telegraph.co.uk/motoring/roadsafety/10570935/Autonomous-cars-is-this-the-end-of-driving.html, last accessed 27 April 2016.

${ }^{78}$ J Gurney, "Sue My Car Not Me: Products Liability And Accidents Involving Autonomous Vehicles" (2013) U. Ill. J.L. Tech. \& Pol'y 247. Utilising a products liability model, Gurney's analysis focuses on four types of drivers : the "Distracted Driver", the "Diminished Capabilities Driver", the "Disabled Driver" and the "Attentive Driver".

${ }^{79}$ S Duffy and J Hopkins, "Sit, Stay, Drive: The Future of Autonomous Car Liability", (2013)16 SMU Sci. \& Tech. L. Rev. 453, 453.

${ }^{80}$ N Kalra, J Anderson and M Wachs, "Liability And Regulation Of Autonomous Vehicle Technologies" (Report) (April 2009), available at http://www.its.berkeley.edu/sites/default/files/publications/UCB/2009/PRR/UCB-ITS-PRR2009-28.pdf, last accessed 25 April 2016.

${ }^{81}$ R Graham, "Getting a handle on driverless cars" (2015), 159 (12) Supp (Personal Injury Focus), SJ 13, 15.

${ }^{82}$ G Yeomans, "Autonomous Vehicles: Handing over Control - Opportunities and Risks for Insurance" 9 (Report) (2014), available at https://www.lloyds.com/ /media/lloyds/reports/emerging\%20risk\%20reports/autonomous\%20 vehicles\%20final.pdf, last accessed 28 April 2016. 
Additionally, it is arguable that no one of these stances, taken in isolation, is necessarily the most correct because there are several interconnected elements of the autonomous vehicle conundrum ${ }^{83}$.

The UK Government has set out a Code of Practice for testing autonomous vehicles $^{84}$ and, in recognition of the fact that regulation lags behind technology, has unveiled plans to create or amend domestic legislation (by summer 2017) so as to provide a sound basis upon which to allocate criminal and civil liability ${ }^{85}$. The development of this legislation will be critical, not least because it will need to address the question of how liability will be apportioned in the period, estimated to be 15-20 years, in which vehicles with several different levels of autonomy penetrate the market while traditional cars, fully operated by humans, remain on the roads ${ }^{86}$.

Ultimately, there are several parties who will be involved in the event of an accident. Legislators, courts and other commentators will face a considerable challenge in determining where liability between these parties will lie. Scholars, for example, have recently devoted considerable attention to liability issues associated with autonomous vehicle technology ${ }^{87}$. Beiker contends, for example, that at the very least, the uncertainty surrounding legal issues necessitates

${ }^{83} \mathrm{~J}$ Boeglin "The Costs Of Self-Driving Cars: Reconciling Freedom And Privacy With Tort Liability In Autonomous Vehicle Regulation" (2015)17 Yale J.L. \& Tech. 171, 175.

${ }^{84}$ Department for Transport, 2015 "The pathway to driverless cars : a Code of Practice for Testing", available at https://www.gov.uk/government/uploads/system/uploads/attachment_data/file/446316/pathwa y-driverless-cars.pdf, last accessed 25 April 2016. Whilst non-statutory, similarly to The Highway Code, a failure to follow the guidance would be a clear indicator of negligence. See Department of Transport, "The Pathway to Driverless Cars" (2015), 9. Report available at https://www.gov.uk/government/uploads/system/uploads/attachment_data/file/401562/pathwa y-driverless-cars-summary.pdf, last accessed 25 April 2016.

${ }^{85}$ Department for Transport, 2015 "The pathway to driverless cars", Department of Transport, "The Pathway to Driverless Cars" (2015), 10. Report available at https://www.gov.uk/government/uploads/system/uploads/attachment_data/file/401562/pathwa y-driverless-cars-summary.pdf, last accessed 25 April 2016.

${ }^{86}$ R Graham, "Getting a handle on driverless cars" (2015), 159 (12) Supp (Personal Injury Focus), SJ 13, 15.

${ }^{87}$ See, for example, J Lederman, M Garrett and B Taylor, "Fault-y Reasoning: Navigating the Liability Terrain in Intelligent Transportation Systems" (2016), 21(1) Public Works Management \& Policy 5. 
additional research into liability matters ${ }^{88}$. Overall, therefore, the lack of clarity regarding the application of criminal and civil law to the several parties detailed above suggests that accountability may be an issue for the courts to decide unless, of course, Parliament intervenes before these legal issues require adjudication.

The final point raised for discussion in relation to autonomous vehicles in this article is the robustness of the technology itself. One of the driving forces behind the implementation of this technology is that autonomous vehicles will have a better safety track record than human drivers. However, technology can (quite literally) crash, and systems are only as sound as their programmers and designers. Hence, to what extent is the technology itself safe? With an increased complexity of hardware and software used in cars, there will also be more that can go wrong. The margin for computer failure is potentially high. Additionally, maliciously interfering with this technology so that it does go wrong could have serious implications for safety. The susceptibility of autonomous vehicle technology to cyber attack is clearly a concern and "always a possibility" 89 . There is now evidence to suggest that autonomous vehicles "could be subject to the whims of online menaces" ${ }^{\prime 90}$, which could hypothetically result in mass catastrophic accidents, in which vehicles are used as weapons potentially of mass destruction. In addition, tying in to the anlaysis above, the vehicle itself would be a repository of personal information about everywhere its user had travelled, how the vehicle had travelled, and everything encountered along the way ${ }^{91}$. Hence, because these cars will collect and share personal data, becoming akin to data centres on wheels, there will be several potential data breach points at which personal information could be extracted. Hackers will be drawn to the range of data that autonomous vehicles will collect because the potential for stealing and reselling this information holds financial allure ${ }^{92}$. Making cars out of computers,

${ }^{88}$ S Beiker, "Legal Aspects of Autonomous Driving" (2012) 52 Santa Clara L. Rev. 1145.

${ }^{89}$ J Boeglin "The Costs Of Self-Driving Cars: Reconciling Freedom And Privacy With Tort Liability In Autonomous Vehicle Regulation" (2015)17 Yale J.L. \& Tech. 171, 181.

${ }^{90} \mathrm{P}$ Campbell, "Data-hungry cyber hackers turn gaze to connected autos", The Financial Times (London 11 May 2016).

${ }^{91}$ D Glancy, "Privacy In Autonomous Vehicles" (2012) 52 Santa Clara L. Rev. 1171, 1180.

${ }^{92}$ P Campbell, "Data-hungry cyber hackers turn gaze to connected autos", The Financial Times (London 11 May 2016). 
therefore, exposes new vulnerabilities, which will increase as autonomous vehicles become more prevalent. In short, the risks of cyber attacks (particularly by criminal organisations ${ }^{93}$ ) will inevitably rise. In response, the UK government has pledged to consider (by end of 2018) how the existing regulatory framework may be developed to ensure autonomous vehicle technology is protected from possible cyber threats ${ }^{94}$ and this is likely to include high standards of system resilience, such as robust data encryption ${ }^{95}$. Carmakers are responding by investing billions in research and bulking up cyber security teams ${ }^{96}$ in the hope that the very architecture of autonomous vehicles can be sufficiently reinforced so as to strengthen security protections. Additionally, legislators will need to define appropriate criminal liability for interference with both the systems within the vehicles and the systems in the external environment on which the vehicles depend for safe operation.

In the meantime, uncertainty as to the apportionment of liability in the event of an accident and the very real risks of cyber-attack, in addition to the privacy issues detailed above, means that the adoption of autonomous vehicle technology may be likely to be met in several quarters with limited appetite. Despite the several benefits, people will be hesitant about embracing technology which potentially compromises their privacy and exposes them to liability and cybersecurity issues not previously considered in traditional driving. It will take time before most people are able to trust autonomous vehicles entirely ${ }^{97}$.

\section{Conclusion}

As detailed above, the development of autonomous vehicle technology has proceeded at

${ }^{93}$ P Campbell, "Data-hungry cyber hackers turn gaze to connected autos", The Financial Times (London 11 May 2016).

${ }^{94}$ Department of Transport, "The Pathway to Driverless Cars" (2015), 38. Report available at https://www.gov.uk/government/uploads/system/uploads/attachment_data/file/401562/pathwa y-driverless-cars-summary.pdf, last accessed 25 April 2016.

${ }^{95}$ G Yeomans, "Autonomous Vehicles: Handing over Control - Opportunities and Risks for Insurance" 16 (Report) (2014), available at https://www.lloyds.com/ /media/lloyds/reports/emerging\%20risk\%20reports/autonomous\%20 vehicles\%20final.pdf, last accessed 28 April 2016.

${ }^{96}$ P Campbell, "Data-hungry cyber hackers turn gaze to connected autos", The Financial Times (London 11 May 2016).

${ }^{97}$ M Taylor and P Maynard, "Self-driving cars" (2015) 21(5), CTLR 133, 134. 
a pace, but whether take-up will match is open to debate. Autonomous vehicle technology has evolved from relatively humble research roots to become what could be a commercially sought after reality. The evolution of this technology has been prolific - the rate of advance arguably being faster than anyone could have predicted. This technological innovation arguably has the ability to produce major potential benefits, not least in terms of significant safety, economic, environmental and social advantages. However, there are also several potential harms, the assessment of which is both exceedingly difficult ${ }^{98}$ and intellectually challenging ${ }^{99}$ (though not insurmountable). As this article has attempted to demonstrate, there will be vast privacy implications, for example. The technological requirements of autonomous vehicles will make it relatively straightforward for users of autonomous vehicles to be extensively tracked and for the vast array of data generated and retained by these vehicles to be utilised in a variety of (as yet unquantified) ways. As addressed herein, there are concerns in relation to privacy as control over private information and misuse of private information and, as regards the latter, what might be considered as reasonable expectations of privacy in the circumstances is open to debate. In tandem, liability issues abound and who bears responsibility for accidents involving autonomous vehicles is not clear-cut or straightforward. The interlocking elements of privacy and liability, including the fact that hacking is a real concern that has yet to be fully grappled with, mean that the legal and regulatory issues surrounding these issues will need to be resolved on a timely basis. Legislators need to act swiftly and decisively because question marks over legal issues may impact the degree to which the technology is adopted. Until the legal landscape becomes clearer, it is understandable that there will be sections of the public who will resist handing over their personal safety on the roads over to a machine and this may ultimately delay the deployment of autonomous vehicle technology. As has been argued, incomplete and inconsistent law could depress the upside of the technology and be a car wreck in its own right ${ }^{100}$. Given the several appealing consequence of the adoption of autonomous vehicle technology, not least surrounding accident avoidance, this is best circumvented. Therefore, whilst it is granted that, to

\footnotetext{
${ }^{98}$ R Graham, "Getting a handle on driverless cars" (2015), 159 (12) Supp (Personal Injury Focus), SJ 13.

${ }^{99}$ D Glancy, "Privacy In Autonomous Vehicles" (2012) 52 Santa Clara L. Rev. 1171, 1173.

${ }^{100}$ E Goodman, "Self-driving cars: overlooking data privacy is a car crash waiting to happen", The Guardian (London 8 June 2016).
} 
date, technological innovation has far out-paced the rate of regulatory innovation, what is now needed is an effective framework in which to manage this technology because it would be a shame if the lack of evolution on the legal side put a handbrake on the technological side, meaning that we could not fully take advantage of the benefits.

Whilst it is acknowledged that legislators, as ourselves, lack the language for the technological future, given the many concerns over privacy and liability and the correlation between these and issues of trust and confidence in the technology, there is a strong argument to suggest that reasoned development of the law in this area cannot happen soon enough. 